\title{
REFLEXÕES CRÍTICAS SOBRE O ENSINO JURÍDICO UNIVERSITÁRIO DAS CIÊNCIAS CRIMINAIS
}

\author{
César Augusto Ferreira São José*
}

\section{RESUMO}

Este artigo toma como pressuposto de suas análises a constatação da crise do ensino jurídico no Brasil e seu reflexo no ensino universitário das ciências criminais. Trata-se de pesquisa bibliográfica que se valerá do método histórico-descritivo para expor tal crise, recortada nos paradigmas pedagógico e epistemológico, e da construção metodológica decolonial para o objetivo de propor reflexões sobre as possibilidades de sua superação. Conclui-se pela proposta de reflexão por uma educação jurídica libertadora informada pelo giro decolonial, enquanto caminho para a compreensão da relação de continuidade entre escravidão e prisão que permeia as hierarquias raciais estruturantes do nosso sistema penal.

PALAVRAS-ChAVE: Crise do ensino jurídico. Ensino jurídico crítico. Ciências criminais. Educação libertadora. Giro decolonial.

\section{CRITICAL REFLECTIONS ON UNIVERSITY LEGAL TEACHING OF CRIMINAL SCIENCES}

\begin{abstract}
This article takes as presupposition of its analyzes the crisis in legal education in Brazil and its impact on university teaching of criminal sciences. This is a bibliographical research that will use the historical-descriptive method to expose this crisis, cut out in the pedagogical and epistemological paradigms, and the decolonial methodological construction aiming to propose reflections on the possibilities of overcoming it. It concludes with the proposal of reflection for a liberating legal education informed by the decolonial turn, as a way to understand the continuity between slavery and prison that permeates the structuring racial hierarchies of our penal system.
\end{abstract}

KEYWORDS: Crisis in legal education. Critical legal education. Criminal sciences. Liberating education. decolonial turn.

\section{INTRODUÇÃO}

\footnotetext{
* Aluno do Mestrado no Programa de Pós-graduação em Direito da Universidade Federal de Sergipe (PRODIR/UFS). Especialista em Ciências Criminais pelo Centro Universitário FG (UniFG). Bacharel em Direito pela Universidade Federal da Bahia (UFBA). Advogado. Lattes: http://lattes.cnpq.br/0579745339519193. ORCID: https://orcid.org/0000-0002-7340-4247. E-mail: cesarsaojose@academico.ufs.br.
} 
O presente trabalho parte da constatação da crise do ensino jurídico no Brasil para, não se limitando apenas ao lugar comum de descrevê-la, contribuir com reflexões sobre as possibilidades de um ensino jurídico crítico das ciências criminais no âmbito universitário. Questionando-nos quais seriam as nuances dessa crise e quais seriam as possibilidades de sua superação, buscamos nos restringir a apontar a crise dos paradigmas pedagógico e epistemológico e, desde seus escombros, pensar o ensino das ciências criminais a partir de outros olhares, ou seja, de outras formas de produzir conhecimento.

Em outras palavras, da temática exposta formulamos a pergunta-problema: diante da crise dos paradigmas pedagógico e epistemológico do ensino jurídico brasileiro, que caminhos podem ser trilhados para a sua superação por um ensino jurídico crítico nas ciências criminais? Nossa hipótese preliminar - menos que uma constatação a ser "posta à prova" - é uma proposta de reflexão no sentido de que uma educação jurídica libertadora informada pelo giro decolonial permite a acurada compreensão de nossa realidade social, em meio a um sistema penal estruturado em hierarquias raciais.

Para isso, pretendemos nos valer, inicialmente, de uma metodologia históricodescritiva da crise do ensino jurídico das ciências criminais e de sua contextualização com o nosso sistema penal para então pensar desde a construção de metodologias decoloniais, ou seja, "procurar respostas para as questões que emergem desde os(as) oprimidos(as), subaltenizados(as), desde a colonialidade do poder, saber e ser, e não meramente responder questões acadêmicas" (DULCI; MALHEIROS, 2021, p. 184-185).

Desse modo, ao refazer o percurso histórico e sistemático de Horácio Wanderlei Rodrigues (2005), temos por objetivo inicial uma visualização do aspecto múltiplo da crise do ensino do Direito - bem como de seu reflexo especificamente no ensino das ciências criminais. É desde esse ponto de partida que apontamos neste trabalho dois dos diferentes aspectos da crise do ensino jurídico para, enquanto objetivos específicos, aprofundar suas respectivas possibilidades de superação, conferindo especial atenção ${ }^{1}$ à crise operacional (acadêmica) pedagógica e à crise estrutural do paradigma epistemológico - em cada um dos tópicos seguintes.

\footnotetext{
${ }^{1}$ Há alguns outros fatores cuja importância reconhecemos, ainda que excedam a delimitação deste trabalho: a crise estrutural do paradigma político-ideológico do ensino jurídico de matriz liberal-conservadora; a crise funcional do ensino jurídico, observada na crise do mercado de trabalho e na de identidade e legitimidade dos operadores do Direito; e, junto à crise operacional de caráter acadêmico, a de caráter administrativo;
} 
Quanto à crise do paradigma pedagógico, buscaremos propor uma mudança na concepção de ensino que tomará por base a pesquisa bibliográfica de trabalhos sobre ensino jurídico influenciados diretamente pelas contribuições de Paulo Freire (2005), em meio às comemorações do centenário de nascimento do célebre educador popular e professor universitário pernambucano.

Por fim, quanto à crise do paradigma epistemológico, buscaremos propor um deslocamento de olhar prévio para demarcar o caráter pedagógico que emerge do giro decolonial que pretendemos promover para um ensino crítico das ciências criminais. Isso decorre do questionamento a referenciais eurocêntricos por um ensino que não se furta à centralidade da categoria raça em suas análises, e possibilite a compreensão e reflexão a respeito do sistema penal brasileiro e do modo como este é estruturado em hierarquias raciais.

\section{A CRISE PERMANENTE DO ENSINO JURÍDICO BRASILEIRO NAS CIÊNCIAS CRIMINAIS}

Horácio Wanderlei Rodrigues (2005) traça um breve percurso histórico do surgimento dos cursos de Direito no país, e é a partir desse trajeto que nós destacamos aquele que nos parece ser o problema perene do ensino jurídico brasileiro: a sua quase completa desvinculação da realidade social do país.

Os primeiros cursos de Direito no Brasil foram criados e instalados no início do período imperial - no Largo do São Francisco, em São Paulo; e no Mosteiro de São Bento, em Olinda - e desde então já se caracterizavam por não ter acompanhado as mudanças que ocorriam na estrutura social. Mesmo superado esse dualismo inicial com a implantação de novos cursos durante o período republicano, chegada a República Velha (ou oligárquica), continuou havendo uma desvinculação entre a instância educacional e a realidade social. No período de 1930 a 1972, com a expansão dos cursos e acesso a eles por parte da classe média, a qualidade do ensino permaneceu baixa, ainda centrada na prática das aulas-conferência e, de maneira geral, com seu conteúdo ainda desvinculado da realidade social. (RODRIGUES, 2005, p. 25-28).

Por um lado, o século XXI trouxe para o ensino jurídico profundas transformações. Entre elas, o atual marco regulatório, em vigor desde 2004; o implemento do sistema de cotas enquanto política afirmativa de reparação histórica nas Universidades Públicas; e os 
financiamentos governamentais que possibilitaram o maior acesso da população ao Ensino Superior, público e privado (SOUZA e ALMEIDA, 2012).

Por outro lado, estabeleceu-se uma avalanche neoliberal que transformou Faculdades de Direito em espécies de cursos técnicos (ou cursinhos) preparatórios para o Exame de Ordem ou para concursos públicos, ao passo que explodiu "o número de faculdades com perfil de franquias comerciais, que propagam um 'mercantilismo das ciências jurídicas', sem qualquer base pedagógica, crítica, humanista, e social" - em suma, o oposto a uma educação libertadora (PIRES e SILVA, 2016, p. 93). Todas aquelas transformações, portanto, não parecem ter alterado o caráter estrutural de dissonância dos cursos de direito com a realidade social da população brasileira.

Horácio Rodrigues (2005, p. 28) situa o período a que denomina contemporâneo - de 1972 até os dias de hoje - como aquele em que foi profícua a produção acadêmica preocupada com o diagnóstico e a solução da crise do ensino do Direito. Antecipando esse movimento, relembra que, já em 1955, San Tiago Dantas proferia aula inaugural na Faculdade Nacional de Direito, no Rio de Janeiro, na qual "relacionava à universidade e à sua burocratização estéril e falta de criatividade e de preocupação com o novo, vendo-a então como mero centro reprodutor de conhecimentos tradicionais" (RODRIGUES, 2005, p. 28).

De fato, no campo do saber penal, Eugenio Raúl Zaffaroni et al (2011, p. 60-61) já situavam as Universidades enquanto parte do sistema penal. Se este é definido como o conjunto de agências que operam a criminalização ou que convergem na sua produção, as Universidades (junto a academias e institutos de pesquisa jurídica e criminológica) são classificadas como agências de reprodução ideológica do sistema penal.

As agências de reprodução ideológica (especialmente as universitárias) não ficam alheias à competição interna - ou externa - contra outras agências de nosso sistema penal ilegítimo. Com isso

correm o risco de perder peso político à medida que deslegitimem o poder punitivo; seus integrantes que contrariem o discurso dominante diminuem seus pontos na briga por assessorarem os operadores políticos ou para galgarem postos nas agências judiciais, e também correm o risco de se verem suplantados por seus opositores nos concursos acadêmicos ou de perderem financiamento para suas pesquisas etc. Como resultado disso, tais agências selecionam seus próprios operadores preferentemente entre os que compartilham o discurso, racionalizando-o ou matizando-o, mas procuram evitar aqueles que o refutam. (ZAFFARONI ET AL, 2011, p. 62) 
Por conta de tais fatores, já há mais de 60 anos, San Tiago Dantas “entendia ser fundamental a recuperação do papel de criação que compete à universidade, sendo essa retomada também necessária no campo do ensino do Direito" (RODRIGUES, 2005, p. 27). Mesmo depois de tanto tempo, não é de se espantar, no entanto, que no mundo jurídico quase nada tenha mudado desde então. Afinal, "a descrição dos cursos por ele [Dantas] efetuada na década de 1950 aplica-se perfeitamente ao que se vê ainda hoje em grande parte das salas de aula de Direito" (RODRIGUES, 2005, p. 28).

No contexto do ensino jurídico brasileiro que, desde sua criação, sempre teve como meta específica funcionar como aparelho ideológico do Estado, o que se ensina via de regra é o Direito (Penal ou Processual Penal) contextualmente construído a partir das crenças político-ideológicas liberal-conservadoras, mas apresentado como neutro e comprometido com a justiça e a democracia.

Para que possamos ter um ensino transformador das ciências criminais, será necessário que ele deixe de ser um aparelho ideológico do Estado - enquanto mera instância (re)produtora das violências de um sistema penal estruturado em hierarquias raciais - e se transforme em uma instância orgânica de construção de um novo imaginário social criativo e comprometido com os valores populares - e não com a manutenção do status quo.

O ensino das ciências criminais - mesmo da Criminologia - tem se vislumbrado como fruto de uma cultura de extrema indiferença do jurista diante da realidade social. Os cursos de Direito, "enquanto locais de circulação dos postulados da dogmática-jurídica, têm estado distantes das preocupações sociais e têm servido, em regra, para a formação de profissionais sem um maior comprometimento com os problemas sociais" (CAOVILLA e BALBINOT, 2017, p. 205).

O ensino do direito, especialmente das ciências criminais, traz em si a herança iluminista que, com sua pretensa racionalidade, acabou por instituir um sistema punitivo que aposta suas fichas no encarceramento em massa e em que pese a criminologia crítica há muito já ter destacado a disfunção desta escolha político-criminal, "a irracionalidade verdadeira da prisão é um dos segredos mais bem guardados em nossa sociedade” (MATHIESEN, 1997, p. 277).

A prisão é "um gigante sobre um solo de barro", conforme alegoria apresentada por Mathiesen, ao denunciar a total irracionalidade da prisão em termos de suas próprias finalidades estabelecidas e jamais alcançadas. Mathiesen cita os cinco objetivos principais não 
alcançados da pena de prisão, quais sejam: reabilitação; intimidação do transgressor; prevenção geral, ou seja, efeitos dissuasórios na sociedade em geral; interdição dos transgressores, retirando-os do convívio social e proporcionalidade, que tampouco pode ser satisfeita por meio do encarceramento, vez que se trata de balancear duas entidades incomensuráveis, que são a transgressão criminal de um lado e o tempo do transgressor de outro,

Assim, conclui Mathiesen pela total irracionalidade da prisão, que se não fosse tão bem guardada por seus três principais defensores (os administradores do sistema criminal; os intelectuais e pesquisadores; e a mídia) a colocariam numa situação tão fragilizada que um clima de desmantelamento das prisões deveria, necessariamente, começar já (MATHIESEN, 1997, p. 270-82). Essa denúncia coloca a academia como um dos pilares de sustentação do sistema prisional moderno, por perpetuar o ideal iluminista, que coloca a punição, materializada, de regra, na pena de prisão, como única resposta ao "mal perpetrado", sem as devidas reflexões críticas.

\section{POR UMA VIRADA DE PARADIGMA PEDAGÓgICO NAS CIENCIAS CRIMINAIS}

A partir de agora, passamos a pensar caminhos e possibilidades para a superação do quadro de crise do ensino jurídico das ciências criminais. A transformação necessária consiste, a princípio, numa mudança de concepção de ensino: do paradigma pedagógico da educação tradicional ou bancária para um paradigma de educação libertadora, em referência às contribuições de Paulo Freire aplicadas ao ensino jurídico (SOUZA e ALMEIDA, 2012; CAOVILLA e BALBINOT, 2017) e das ciências sociais (PENNA, 2014). Afinal, nos termos pensados pelo educador pernambucano, na educação bancária

o saber é uma doação dos que se julgam sábios aos que julgam nada saber. Doação que se funda numa das manifestações instrumentais da ideologia da opressão - a absolutização da ignorância, que constitui o que chamamos de alienação da ignorância, segundo a qual esta se encontra sempre no outro. $\mathrm{O}$ educador que aliena a ignorância, se mantém em posições fixas invariáveis. Será sempre o que sabe, enquanto os educados serão sempre os que não sabem (FREIRE, 2005, p. 67) 
De fato, Horácio Rodrigues (2005, p. 53) nos alerta que, na área pedagógica, o ensino do Direito apresenta-se como um dos principais focos ainda existentes, na universidade brasileira, do paradigma de educação tradicional, ou bancária, que vê o aluno como um receptor passivo do conteúdo apresentado em sala de aula pelo professor. A "realidade", nesses termos, é algo que será a ele transmitido através da educação formal. Trata-se da concepção de que o conhecimento humano possui um caráter cumulativo, e de que a inteligência seria a capacidade de armazenar informações, artigos de lei, enunciados de súmula de tribunais, posições doutrinárias e afins.

Na visão bancária de educação, "não há criatividade, não há transformação, mantémse as coisas exatamente como estão, sem caráter crítico, sem estímulo à mudança, a favor de que as opressões se perpetuem" (CAOVILLA e BALBINOT, 2017, p. 206), o que atende aos interesses de um sistema penal ilegítimo e (re)produtor de violências, como o brasileiro. Com isso, Paulo Freire é quem "nos traz ferramentas por meio das quais torna-se possível pensar uma pedagogia crítica e transformadora, que potencialize a ação das forças comprometidas com a transformação social" (SOUZA e ALMEIDA, 2012, p. 200).

O paradigma pedagógico de Freire parte de um processo que, como nos alerta Camila Penna (2014, p. 195), "só tem sentido na medida em que o educando é respeitado e sua forma de perceber e interpretar a realidade são investigadas profundamente pelo educador e consideradas no momento de se construir o conteúdo programático". Afinal, parte-se da premissa de um processo de ensino estabelecido a "partir de uma realidade que seja próxima e acessível ao educando, evitando a imposição de conteúdos programáticos alheios e formados a priori, sem nenhuma relação com a realidade vivida pelos educandos, e, portanto alienante e de difícil compreensão" (PENNA, 2014, p. 195).

Mais ainda, Paulo Freire concebe uma prática pedagógica crítica, uma pedagogia da autonomia, a partir da qual "o educador tem a responsabilidade de comunicar certo conteúdo de modo a refinar a curiosidade do educando, não apenas se dedicando a explicar com clareza certo conteúdo para que o aluno o fixe" (SOUZA e ALMEIDA, 2012, p. 210). A promoção dessa autonomia diz respeito a iniciar o educando no aprendizado das ciências criminais no intuito de que, com o instrumental teórico adequado à nossa margem $^{2}$, produza sua própria compreensão do objeto, em vez de apenas recebê-la. Trata-se de uma importante estratégia

\footnotetext{
${ }^{2}$ Aqui fazemos referência à aproximação ao estudo da Criminologia desde a margem latino-americana, realizada por Eugenio Raúl Zaffaroni (1988).
} 
para a superação da desvinculação do ensino das ciências criminais com a realidade social do país e de seu sistema penal.

Além de compreender melhor o atual quadro de ilegitimidade no bojo do nosso sistema penal marginal, caberá tanto a educador como a educando o compromisso ético de transformá-lo, visto que "o propósito da educação libertadora é o de superar a visão fatalista da realidade como eterna e imutável, passando-se à percepção de que ela é construída pelos homens e passível de ser transformada" (PENNA, 2014, p. 190).

Por fim, se é verdade que "neste processo educacional, o educador deve se esforçar para entregar todas as ferramentas que possibilitem tal produção autônoma do conhecimento" (SOUZA e ALMEIDA, 2012, p. 210), uma dessas ferramentas será o olhar decolonial trazido pelos estudos pós-coloniais, que significarão neste trabalho a ruptura com o paradigma epistemológico tradicional dos cursos de Direito, de base predominantemente normativista.

\section{POR UM GIRO DE PARADIGMA EPISTEMOLÓGICO NO ENSINO DAS CIÊNCIAS CRIMINAIS}

Retomando o pensamento de Horácio Wanderlei Rodrigues, o ato de "ensinar Direito é sempre ensinar urna das formas possíveis de ver e aplicar o Direito", e é por conta disso que “a questão epistemológica se apresenta como principal sempre que se trata de questões educacionais" (RODRIGUES, 2005, p. 40). Como discutimos, a crise estrutural do ensino jurídico é evidenciada na percepção de que o conhecimento jurídico encontra-se "aprisionado por um discurso liberal conservador e por uma pedagogia dogmática e formalista" (MACHADO, 2009, p. 18).

Esse paradigma ideológico liberal-conservador é reproduzido por um paradigma epistemológico positivista, no qual a norma é o objeto privilegiado do conhecimento jurídico, marcado pela crença na neutralidade (ou ao menos objetividade) do sujeito cognoscente e pelo emprego do método lógico-formal. A influência desse paradigma epistemológico ainda se faz presente na estrutura acadêmica, em especial na concepção de ensino vigente (tradicional e bancária), que mantém fortes vínculos com o positivismo e com a sua concepção de ciência e verdade (RODRIGUES, p. 32-33).

A essa altura já não há dúvidas acerca da necessidade de transcender o paradigma do positivismo jurídico e seu método lógico-formal, que tem servido apenas para apreender o 
dever-ser enquanto produzem uma visão unidimensional da realidade social. Nesse contexto, tem sido tarefa das correntes críticas do pensamento jurídico a busca por romper com "o mito da neutralidade do direito, demonstrando que a interpretação e aplicação dogmática da lei, de forma supostamente neutra, e equidistante dos conflitos sociais, em certos casos, pode ser uma servil reprodução dos interesses da classe econômica dirigente, os quais se encontravam previamente consolidados na norma jurídica” (MACHADO, 2009, p. 52).

Afinal, é essa visão mesma que "transforma o ensino do Direito em mera repetição e exegese dos textos legais" (RODRIGUES, 2005, p. 42) ou em pouca coisa além disso; ao passo que a busca por autossuficiência no jurídico torna os cursos, regra geral, incompetentes para fazer compreender qualquer realidade um palmo além dos códigos e das jurisprudências.

É pensando seriamente na necessidade de "construir alternativas que realmente busquem modificar as estruturas vigentes na teoria, na práxis e no ensino do Direito" (RODRIGUES, 2005, p. 44), que propomos também ao ensino das ciências criminais - num deslocamento anterior à mudança de paradigma na concepção de ensino - o giro decolonial proposto por Camila Penna (2014) ao ensino das ciências sociais, assinalado no caráter pedagógico da perspectiva pós-colonial nesse campo do saber.

Com efeito, Penna (2014) volta sua análise à retomada de alguns pontos de convergência entre o pensamento pós-colonial latino-americano e a obra de Paulo Freire, em especial Pedagogia do Oprimido, de onde pretende extrair argumentos que justifiquem maior atenção à dimensão pedagógica daquela literatura para o campo das ciências sociais e acrescentamos - também para as ciências criminais. Essa dimensão pedagógica se apresentaria na medida em que o pensamento pós-colonial questiona os referenciais eurocêntricos a partir dos quais é produzido o conhecimento no campo das ciências sociais e criminais.

Tanto a obra de Freire quanto o pensamento pós-colonial reconhecem o tema da dominação cognitiva que sustenta a dominação material - para o primeiro, sob a noção de invasão cultural; para o segundo como colonização do ser, que leva o sujeito a pensar e ver o mundo a partir de categorias que o colocam na posição de oprimido, e que só será superada por meio da explicitação de alguns dos mitos sobre os quais a dominação se fundamenta (PENNA, 2014, p. 188-191).

Assim, a atitude de adotar como conteúdo programático a apresentação dos discursos coloniais como mitos forjados com vistas a justificar a dominação dos colonizados, bem como 
a repercussão atual desses discursos, tem, assim como o projeto de Freire, um caráter pedagógico. Em especial, porque o giro decolonial promove o surgimento de um novo lugar de fala, que se torna possível na medida em que o próprio discurso colonial é colocado em xeque, se tornando o centro da análise - o que faz parte de um paradigma mais amplo: o paradigma da colonialidade (PENNA, 2014) pensado em conjunto com a modernidade:

No pensamento pós-colonial a colonialidade seria a face oculta da modernidade, que surge do sentimento de inferioridade imposto nos seres humanos que não se encaixam no modelo eurocêntrico. A modernidade só pode ser pensada em coexistência e simultaneidade com a colonialidade, na medida em que a identificação como "moderno" e "civilizado" se afirma a partir da categorização da colônia como "bárbara" e "atrasada". E nesse sentido a escravidão, o genocídio e a exploração também são parte da modernidade, estão na face da colonialidade (PENNA, 2014, p. 194).

De acordo com Aníbal Quijano (2005), a colonialidade cria um novo padrão de poder cujo eixo central é a raça, ou seja, a classificação da população mundial sobre a ideia de raça - forjada na colonização da América, com o advento da qual convergem dois processos: a codificação (e posterior naturalização) da diferença entre dominantes e dominados em termos de raça e a articulação de todas as formas históricas de controle do trabalho em torno do mercado mundial.

É com a invasão da América que toma lugar essa nova codificação para a distribuição internacional do trabalho com critério na ideia de raça: “em outras palavras as raças inferiores não deveriam ser destinadas ao trabalho assalariado, mas sim ao trabalho escravo" (PENNA, 2014, p. 185). Essa percepção é de sobremaneira importante ao estudo das ciências criminais a partir do momento em que se argumenta uma relação de continuidade entre escravidão e prisão nos sistemas penais estruturados em hierarquias raciais, como o nosso.

Tomando por influência o pensador martinicano Frantz Fanon (2008), em Peles Negras, Máscaras brancas, nós podemos empregar os conceitos de zona do ser e zona do não ser para explicitar as premissas que subsidiam esse trecho do trabalho. Com efeito, o projeto moderno-colonial mobilizou a categoria raça para instituir uma linha que separa com um abismo as duas zonas: a do humano (zona do ser) e a do não humano (zona do não ser).

Pressupomos, como o faz Rita Laura Segato (2007), a existência de uma relação de continuidade entre a servidão e a escravidão do passado e as prisões do presente que torna 
possível a percepção naturalizada do sofrimento e da morte dos povos não brancos, os que ocupam a zona do não ser. Trata-se de uma concepção da história como trama contínua, ou seja, a noção de que os episódios de Terror de Estado na América Latina podem ser compreendidos como uma história única, antiga e principalmente contínua. Assim, esses episódios violentos da atualidade são todos parte da sequência iniciada pelo extermínio e pela expropriação que fundaram a colonialidade.

Ana Flauzina e Thula Pires (2019, p. 2129) apontam que a correspondência indissociável entre racismo e encarceramento no Brasil faz com que a sociedade brasileira fomente com os sujeitos aprisionados o mesmo tipo de relação que fomenta com as pessoas negras - uma relação de distanciamento entre brancos e não brancos, entre encarcerados e "livres".

De fato, as hierarquias de humanidade que endossam essa relação de distanciamento "não eximem a zona do não ser de sofrer a violência de Estado, estando dentro ou fora das grades. A violência sobre a zona do não ser como norma se produz em relação ao exercício da liberdade e da legalidade pela zona do ser, como atributo exclusivo" (FLAUZINA e PIRES, 2019, p. 2129).

O cárcere apresenta de forma extremada/concentrada as violências de Estado que são mobilizadas para desumanizar os mesmos grupos fora do cárcere (FLAUZINA e PIRES, 2019, p. 2130). As prisões da América Latina são majoritariamente ocupadas pelos deserdados do processo de colonização. Conforme Segato (2007, p. 150), “es del orden racial de donde emana el orden carcelario, pero éste lo retroalimenta. Y el orden racial es el orden colonial'.

Para Michelle Alexander (2017), o sistema de justiça criminal sempre esteve empenhado em manter normalizada a sua estruturação em hierarquias raciais. Essa ordem racial é pensada por ela com o emprego da expressão casta racial "para denotar um grupo racial estigmatizado e preso em uma posição de inferioridade pelo direito e pelos costumes. $\mathrm{O}$ Jim Crow [legislação segregacionista] e a escravidão foram sistemas de casta racial. E o atual sistema de encarceramento em massa também o é." (ALEXANDER, 2017, p. 50).

Em sua apresentação à edição brasileira de A Nova Segregação, Ana Flauzina afirma que o maior mérito do livro de Alexander está no reposicionamento do racismo em sua relação com o sistema de justiça criminal. Para Flauzina (2017, p. 12) "a perspectiva de Alexander foge às análises convencionais, invertendo a retórica que torna o racismo um 
subproduto das práticas do controle penal. De forma clara e direta, a autora nos mostra que o sistema de justiça criminal é, em verdade, um dos produtos diletos do racismo".

Sobre o caso brasileiro, a impressão de Juliana Borges (2018, p. 16-17) não é diferente:

O sistema de justiça criminal tem profunda conexão com o racismo, sendo o funcionamento de suas engrenagens mais do que perpassados por esta estrutura de opressão, mas o aparato reordenado para garantir a manutenção do racismo e, portanto, das desigualdades baseadas na hierarquização racial. Além da privação de liberdade, ser encarcerado significa a negação de uma série de direitos e uma situação de aprofundamento de vulnerabilidades. Tanto o cárcere quanto o pós-encarceramento significam a morte social destes indivíduos negros e negras que, dificilmente, por conta do estigma social, terão restituído o seu status, já maculado pela opressão racial em todos os campos da vida, de cidadania ou possibilidade de alcançá-la. Esta é uma das instituições mais fundamentais no processo de genocídio contra a população negra em curso no país.

É com essa incursão nas correntes de pensamento a respeito da (re)produção de hierarquias raciais que estruturam o sistema penal brasileiro que percebemos o quanto todos esses mitos do eurocentrismo, passados por gerações às classes oprimidas por meio da educação bancária - inclusive no ensino jurídico-penal, culminaram na imersão das consciências dos colonizados em um processo colonização do ser. Esse tipo de colonização, tal qual a imersão da consciência dos oprimidos, leva à internalização e naturalização das categorias do eurocentrismo. Ou seja, na categorização de si próprios como inferiores, animalizados, atrasados, selvagens, e não-civilizados dentro de um ideal de civilização eurocêntrico que é em si um mito construído com um determinado propósito - o de justificar a dominação e a exploração (PENNA, 2014).

É por isso que, por fim, concluímos retomando um aspecto importante da construção teórica elaborada por Camila Penna (2014) sobre a dimensão pedagógica da literatura póscolonial no campo das ciências sociais. Assim como argumentamos a respeito das ciências criminais, trata-se de compreendermos a nossa realidade marginal latino-americana como marcada por um processo histórico e sociológico de opressão e colonização. É uma questão "que em si pressupõe um ponto de partida, ou um lugar de fala, distinto do lugar a partir do qual o conhecimento hegemônico é enunciado. E isto marca nossa produção, nossos quadros interpretativos, nossas formas de compreender e classificar o mundo" (PENNA, 2014, p. 197). 


\section{CONSIDERAÇÕES FINAIS}

Para a transformação do ensino das ciências criminais, será necessário deixar de operá-lo como parte de um aparelho ideológico do Estado - mera instância (re)produtora das violências de um sistema penal estruturado em hierarquias raciais - e transformá-lo no âmbito universitário em uma instância orgânica de construção de um novo imaginário social criativo e comprometido com os valores populares e não com a manutenção do status quo.

A partir de um breve percurso histórico do surgimento dos cursos de Direito no país, pudemos destacar aquele que nos parece ser o problema perene do ensino jurídico brasileiro: a sua quase completa desvinculação da realidade social do país. Ao pensar, em específico, o ensino das ciências criminais, o que se vislumbra é uma reprodução da dogmática penal dissociada dos dados concretos da realidade permeada em suas análises pela permanência do positivismo criminológico.

O paradigma pedagógico do ensino jurídico permanece sendo um dos principais focos ainda existentes, na universidade brasileira, da chamada educação tradicional, ou bancária, que compreende o aluno como um receptor passivo do conteúdo apresentado em sala de aula. Por isso o rompimento desse paradigma por uma educação libertadora é o caminho pelo qual concluímos dever seguir.

Mas não o faremos sem antes promover um deslocamento epistêmico, um giro decolonial, a partir da necessidade de construir alternativas que realmente busquem a transformação das estruturas vigentes na teoria, na práxis e no ensino das ciências criminais num deslocamento anterior à mudança de paradigma na concepção de ensino. É com elas que percebemos o quanto todos esses mitos do eurocentrismo, passados por gerações às classes oprimidas por meio da educação bancária - inclusive no ensino jurídico - culminaram na imersão das consciências dos colonizados em um processo colonização do ser.

O pensamento decolonial tem importante valor pedagógico enquanto proposta questionadora das categorias teóricas e formas de raciocínio já naturalizadas como legítimas, em especial no que diz respeito àquelas formuladas sob o paradigma da dogmática jurídicopenal tradicional. Ao fim e ao cabo, reforçamos nossa proposta de reflexão por uma educação jurídica libertadora informada pelo giro decolonial, o que nos permite a acurada compreensão da relação de continuidade entre escravidão e prisão que permeia as hierarquias raciais estruturantes do nosso sistema penal. Essa virada de paradigma epistêmico e pedagógico é o 
caminho propomos seguir para a superação da crise do ensino tradicional rumo a um ensino jurídico crítico das ciências criminais.

\section{REFERÊNCIAS}

ALEXANDER, Michelle. A nova segregação: Racismo e encarceramento em massa. 1 ed. São Paulo, 2017.

BORGES, Juliana. O que é encarceramento em massa? Belo Horizonte: Letramento, 2018.

CAOVILLA, Maria Aparecida Lucca; BALBINOT, Carmelice Faitão; Para uma Educação Jurídica Libertadora: reflexões freireanas. In: DICKMANN, Ivo; et al. Pedagogia da memória. Chapecó: Sinproeste, 2017.

DULCI, Tereza Maria Spyer; MALHEIROS, Mariana Rocha. Um giro decolonial à metodologia científica: apontamentos epistemológicos para metodologias desde e para a América Latina. Revista Espirales, [S. 1.], p. 174-193, 2021. Disponível em: https://revistas.unila.edu.br/espirales/article/view/2686. Acesso em: 1 set. 2021.

FANON, Frantz. Pele negra, máscaras brancas. Salvador: EDUFBA, 2008.

FLAUZINA, Ana Luiza Pinheiro. Apresentação. In: ALEXANDER, Michelle. A nova segregação: Racismo e encarceramento em massa. 1 ed. São Paulo, 2017.

FLAUZINA, Ana; PIRES, Thula. Cartas do Cárcere: horizontes de resistência política. Revista Direito e Práxis, Rio de Janeiro, Vol. 10, N.03, 2019 p. 2117-2136.

FREIRE, Paulo. Pedagogia do Oprimido. 47 ed. Petrópolis: Vozes, 2005.

MACHADO, Antônio Alberto. Ensino jurídico e mudança social. 2 ed. São Paulo: Expressão Popular, 2009. 
MATHIESEN, Thomas. A caminho do século XXI: abolição, um sonho impossível? In: Conversações abolicionistas: uma crítica do sistema penal e da sociedade punitiva. São Paulo: IBCCrim, 1997, pp. 263-87.

PENNA, Camila. Paulo Freire no pensamento decolonial: um olhar pedagógico sobre a teoria pós-colonial latino-americana. Revista de Estudos \& Pesquisas sobre as Américas, v. 8, n. $2,2014$.

PIRES, Thula Rafaela de Oliveira; SILVA, Gisele Alves De Lima. Movimentos de Política Criminal e Ensino Jurídico. In: BIRNFELD, Carlos André; SANCHES, Samyra Haydêe Dal Farra Naspolini; MEZZAROBA, Orides (coord.). Direito, educação, epistemologias, metodologias do conhecimento e pesquisa jurídica [Recurso eletrônico on-line]. Florianópolis: CONPEDI, 2016.

QUIJANO, Aníbal. Colonialidade do poder, eurocentrismo e América Latina. In: LANDER, Edgardo. A colonialidade do saber: eurocentrismo e ciências sociais. Perspectivas latinoamericanas. Ciudad Autónoma de Buenos Aires, Argentina: CLACSO - Consejo Latinoamericano de Ciencias Sociales, 2005.

RODRIGUES, Horácio Wanderlei. Pensando o ensino do direito no século XXI: diretrizes curriculares, projeto pedagógico e outras questões pertinentes. Florianópolis: Fundação Boiteux, 2005.

SOUZA, Marcel Soares de; ALMEIDA, Marina Corrêa de. Da contradogmática à práxis. Duas contribuições para uma educação jurídica crítica. Revista Eletrônica Faculdade de Direito de Franca, v. 5, n. 1, jul. 2012.

ZAFFARONI, Eugenio Raúl. Criminología. Aproximación desde un margen. Bogotá: Temis, 1988. 
ZAFFARONI, Eugenio Raúl; BATISTA, Nilo; ALAGIA, Alejandro; SLOKAR, Alejandro. Direito Penal Brasileiro: primeiro volume - Teoria Geral do Direito Penal. 4 ed. Rio de Janeiro: Revan, 2011. 